\title{
The Ecotopes and Evolution of Triatomine Bugs (Triatominae) and their Associated Trypanosomes
}

\author{
Michael Gaunt, Michael Miles ${ }^{+}$ \\ Pathogen Molecular Biology and Biochemistry Unit, Department of Infectious and Tropical Diseases, \\ London School of Hygiene and Tropical Medicine, Keppel Street, London WC1E 7HT, UK
}

Triatomine bug species such as Microtriatoma trinidadensis, Eratyrus mucronatus, Belminus herreri, Panstrongylus lignarius, and Triatoma tibiamaculata are exquisitely adapted to specialist niches. This suggests a long evolutionary history, as well as the recent dramatic spread a few eclectic, domiciliated triatomine species. Virtually all species of the genus Rhodnius are primarily associated with palms. The genus Panstrongylus is predominantly associated with burrows and tree cavities and the genus Triatoma with terrestrial rocky habitats or rodent burrows. Two major sub-divisions have been defined within the species Trypanosoma cruzi, as T. cruzi 1 (Z1) and T. cruzi 2 (Z2). The affinities of a third group (Z3) are uncertain. Host and habitat associations lead us to propose that T. cruzi 1 (Z1) has evolved in an arboreal, palm tree habitat with the triatomine tribe Rhodniini, in association with the opossum Didelphis. Similarly we propose that $\mathrm{T}$. cruzi $(\mathrm{Z2})$ and $\mathrm{Z} 3$ evolved in a terrestrial habitat in burrows and in rocky locations with the triatomine tribe Triatomini, in association with edentates, and/or possibly ground dwelling marsupials. Both sub-divisions of T. cruzi may have been contemporary in South America up to 65 million years ago. Alternatively, T. cruzi 2 (Z2) may have evolved more recently from T. cruzi 1 (Z1) by host transfers into rodents, edentates, and primates. We have constructed a molecular phylogeny of haematophagous vectors, including triatomine bugs, which suggests that faecal transmission of trypanosomes may be the ancestral route. A molecular clock phylogeny suggests that Rhodnius and Triatoma diverged before the arrival, about 40 million years ago, of bats and rodents into South America.

Key words: triatomine bugs - ecotopes - palms - Rhodnius - marsupials - Didelphis - edentates -

Trypanosoma cruzi - evolution - phylogenetics

Phenotypic diversity and genotypic diversity of Trypanosoma cruzi were described in a series of publications in the $70 \mathrm{~s}$ and $80 \mathrm{~s}$. At least two major subdivisions within the species were defined, initially as principal zymodemes (reviewed in Stothard et al. 1999, Anon 1999). Contemporary papers on $T$. cruzi in the Amazon basin of Brazil, described the habitats and vertebrate hosts of triatomine bug species and their roles as vectors of T. cruzi and T. rangeli (Miles et al. 1981a,b, 1983). Here we revisit these early studies in the context of (a) more recent molecular approaches to understanding T. cruzi genotypes, and (b) new research on the phylogeny of triatomine bugs. We speculate on the evolution of triatomine bugs and $T$. cruzi, and provide evidence for key elements of their evolutionary history.

Funded by the Wellcome Trust and the European Commission ALFA programme.

${ }^{+}$Corresponding author. Fax: +442076368739. E-mail: michael.miles@1shtm.ac.uk

Received 13 April 2000

Accepted 15 May 2000
TRIATOMINE BUGS SHOW EXQUISITE ADAPTATION TO THEIR NATURAL ECOTOPES

Pioneering and life-long studies have provided a framework of understanding for the taxonomy of triatomine bugs (Lent \& Wygodzinsky 1979, Carcavallo et al. 1998). In contrast, understanding of the biology of individual triatomine species in their natural habitats is fragmentary; for some species natural ecotopes have not been described.

Research on sylvatic ecotopes of triatomines in Amazon forest was aided by spool and line tracking to trace mammals back to their nests and refuges (Miles et al. 1981a,b). Observations from the Brazilian Amazon basin and elsewhere provide evidence that many triatomine species are exquisitely adapted to their natural ecotopes (Fig. 1). Thus, Microtriatoma trinidadensis is a small species which is dorsoventrally flattened and lives between the folded leaves of opossum (Didelphis) nests; its coloration corresponds with the hue of the leaves among which it hides. Eratyrus mucronatus lives in large hollow trees; adults feed on porcupines (Coendou prehensilis) and young instars can feed on the haemolyph of large arachnids (Amblypygi) which inhabit hollow trees. Belminus herreri lives beneath the scaly bark of 


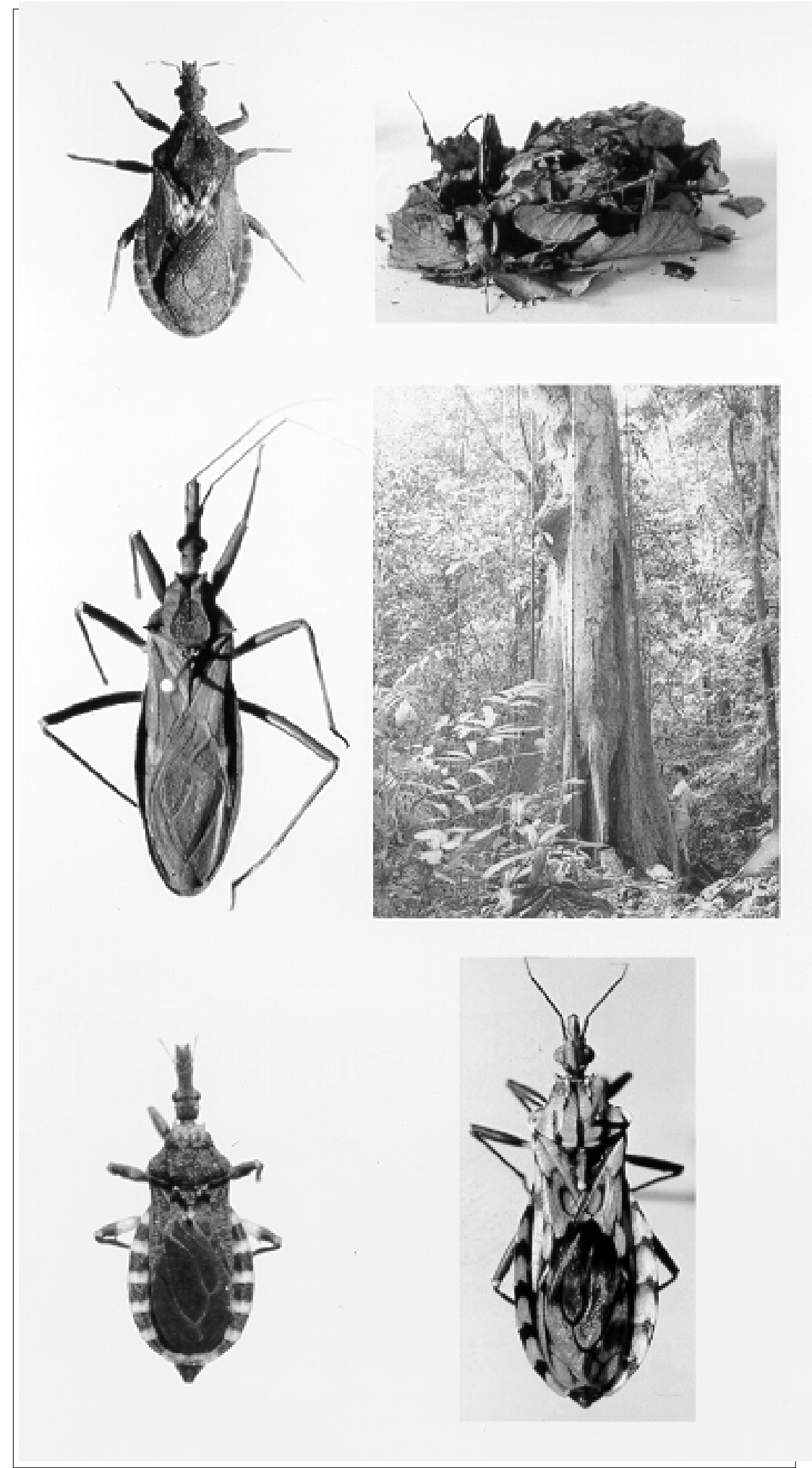

Fig. 1: many triatomine species are adapted to specialist niches (see text). Top: Microtriatoma trinidadensis and its habitat, the leaves of a Didelphis nest. Centre: Eratyrus mucronatus and hollow tree inhabited by porcupines and arachnids. Bottom: Belminus herreri (left) and Panstrongylus lignarius (right) with its bark-like camoflauge colouration. 
large forest trees where it is associated with the lizard Thecadactylus; it appears to be an obligate lizard feeder. Panstrongylus lignarius adults move freely over the surface of Amazonian trees and will approach disturbances in the forest: their coloration corresponds beautifully with the bark on which they reside, whilst younger stages lacking the camouflage, live in tree holes. Triatoma tibiamaculata (in the State of Bahia, Brazil) lives in bromeliad epiphytes with pinkish camouflage that ideally suits its habitat at the junction between the epiphyte and the host tree. The peridomestic species $T$. rubrofasciata is almost invariably associated with the ship's rat (Rattus rattus) and is fortunately reluctant to feed on most other hosts including humans. Some triatomine species, however, such as Rhodnius prolixus and $P$. megistus are obviously eclectic in their feeding, without obligate hosts. Nevertheless, the examples above suggest that adaptation of triatomine species to specialist niches is commonplace, not exceptional.

The obscure spatial, feeding or temporal characteristics of some triatomine niches may reflect a lack of information. One example is the difficulty in defining distinct niches for $R$. pictipes and $R$. robustus, both of which may be found in the same palm tree. Yet, $R$. pictipes appears to be more commonly associated with the "mucajá" palm (Acrocomia sclerocarpa) and $R$. robustus with the "inajá" (Maximiliania regia) or the closely related "babaçu" Orbigyna speciosa (Miles et al. 1983). These palm species prefer different soil types and have different, albeit partially overlapping geographical distributions. We suspect that the darker colour of $R$. pictipes and pinker light brown hue of $R$. robustus may be indicative of their different palm tree habitats. Certainly, the coloration of $R$. pictipes blends perfectly with the dry bases of Acrocomia palm fronds. Distinct feeding niches might also be provided by subtle host preferences, for example, $R$. robustus has been tentatively associated with the marsupial Caluromys philander (Caluromyidae). The greater ease with which $R$. robustus adapts to laboratory colonies, compared to $R$. pictipes, may also reflect subtle microhabitat differences. Finally present geographical distribution may in part be due to the contraction and expansion of forest relicts with climatic change.

The specialist adaptation of triatomine species to distinct niches implies a long evolutionary history, as well as the dramatic more recent expansion of a few eclectic, domiciliated species.

\section{HABITAT TRENDS OF RHODNIUS, PANSTRONGYLUS AND TRIATOMA}

Virtually all Rhodnius species are primarily associated with palm tree habitats (Lent \&
Wygodzinsky 1979, Miles 1979, Carcavallo et al. 1998). Exceptions are R. domesticus, reported from bromeliads and hollow trees, and $R$. paraensis, which has only been found once, in a tree hole refuge of the arboreal spiny rat Ehimys chrysurus. As mentioned, some Rhodnius species may be associated with particular types of palm, further examples being $R$. brethesi with the palm Leopoldinia piassaba and R. ecuadoriensis with Phytelephas. In addition to coloration (see above) other features of Rhodnius may be adapted to life in palms, for example, the climbing organs might assist movement along frond stems and trunks, which are particularly smooth in many palm species. It follows the distribution of sylvatic Rhodnius in Latin America broadly coincides with the distribution of palm trees. It is also not surprising that many species of Rhodnius will feed avidly on birds, which commonly nest in palms, especially on the fringes of forests and in open woodland. The genus Psammolestes, which is closely related to Rhodnius can be found in palms but especially in the nests of Anumbius and Phacellodomus birds.

We believe therefore that the triatomine genus Rhodnius, has a history of evolution in the palm tree habitat in Latin America.

Although some Panstrongylus species, such as $P$. megistus, can be found in palm crowns, all species are predominantly associated with terrestrial burrows, tree root cavities and/or arboreal tree holes. A sylvatic habitat of the highly domiciliated species $P$. megistus is arboreal tree holes with Didelphis (Miles et al. 1982). We suggest that the genus Panstrongylus is primarily associated with burrows and tree cavities.

A survey of the habitat associations of species of the genus Triatoma (Miles 1979) reveals that at least twenty Triatoma species are associated with terrestrial rocky habitats or rodent burrows. An exception is T. sordida, which like Psammolestes seems to feed preferentially on birds. We suggest that the genus Triatoma has evolved predominantly in terrestrial, rocky habitats. The genera Panstrongylus and Triatoma are considered to be closely related (tribe Triatomini) but more distant from Rhodnius (tribe Rhodniini).

These links between the three triatomine genera and habitat type are summarised in Table I. Although not absolute, these associations are remarkable in view of the many opportunities that must have arisen for the colonisation of alternative niches.

Indeed the substrate preferences of Rhodnius, Panstrongylus and Triatoma are reflected in their distribution within infested houses. Thus, $R$. prolixus can give heavy infestations in palm roofs; P. megistus is primarily associated with earth and 
wooden substrates of timber framed, mud walled houses but seldom colonises palm roofs, and $T$. infestans can be found in good quality housing and in tiled roofs.

\section{HABITAT AND HOST ASSOCIATIONS OF T. CRUZI 1 (Z1), T. CRUZI 2 (Z2) AND Z3}

T. cruzi $\mathrm{Z} 1$ and $T$. cruzi $\mathrm{Z} 2$ were originally described on the basis of isoenzyme phenotypes as major subdivisions within the species $T$. cruzi. They were more widely separated by isoenzyme criteria than unequivocal biologically distinct species of the genus Leishmania (Miles et al. 1983). $\mathrm{Z} 3$ was described as a group without certain affinities to Z1 or Z2. Over the last two decades a plethora of molecular methods including random amplification of polymorphic DNA (RAPD), determination of ribosomal and mini-exon DNA sequence polymorphisms, and microsatellite analysis have confirmed the integrity of two major subdivisions within $T$. cruzi, corresponding to $\mathrm{Z} 1$ and Z2. A recent workshop (Anon 1999) attempted to consolidate various terminologies (and to remove confusion that arose when $\mathrm{Z} 1$ and $\mathrm{Z} 2$ were named on ribosomal DNA sequence data as lineage 2 and lineage 1 respectively) by naming the two subdivisions as $T$. cruzi 1 (Z1) and T. cruzi 2 (Z2). There is marked heterogeneity also within $T$. cruzi 1 and T. cruzi 2 , particularly within the latter. Tibayrenc and his collaborators have studied this heterogeneity in great detail (Bastrenta et al. 1999). Some T. cruzi strains appear to have characteristics typical of both $T$. cruzi 1 and $T$. cruzi 2 , suggesting the occurrence of genetic recombination and hybrid forms (Stothard et al. 1999). Although T. cruzi appears to be predominantly clonally propagated, field and experimental evidence implies a capacity for genetic exchange, at least in T. cruzi 1 (Stothard et al. 1999). A few T. cruzi isolates from the Amazon basin appear to share T. cruzi 1 (Z1) and Z3 characters (Povoa et al. 1984). More de- tailed molecular studies suggest Z3 has closest affinities with $T$. cruzi 2 (Z2).

A large number of $T$. cruzi isolates from the Amazon basin have been identified as $T$. cruzi 1 (Z1) or Z3, although this work is far from comprehensive as not all mammal or triatomine species are well represented in these surveys (Povoa et al. 1984). Nevertheless, T. cruzi 1 (Z1) was consistently isolated from the common opossum $(D$. marsupialis) and was also found in $R$. robustus and R. pictipes (Povoa et al. 1984, Carrasco et al. 1996). This accords with the frequent isolation of $T$. cruzi 1 (Z1) from Didelphis elsewhere. We concluded that there is a close but not absolute association between palm trees, Rhodnius species, T. cruzi 1 (Z1) and Didelphis (Table I).

The T. cruzi subgroup Z3, with as yet unresolved affinities, was associated in the Amazon basin with an edentate, the armadillo Dasypus novemcinctus, and with the terrestrial marsupial Monodelphis brevicaudata (Povoa et al. 1984). Z3 was also isolated from P.geniculatus, the triatomine bug commonly found in armadillo burrows. We concluded that Z3 may be primarily associated with the terrestrial habitat and ground dwelling hosts (Povoa et al. 1984, Table I).

T. cruzi 2 (Z2) predominates in domestic transmission cycles in the southern cone countries of South America [Argentina, Bolivia, Brazil, Chile, Paraguay and (presumably) Uruguay] (Miles et al. 1984, Chapman et al. 1984), whereas T. cruzi 1 (Z1) predominates in domestic transmission cycles to the north of the Amazon basin. T. infestans is thought to have spread from a sylvatic habitat in Bolivia among rocks inhabited by guinea pigs (Cavia) throughout the entire region of domestic T. cruzi transmission in the southern cone countries. This led us to suggest that there is a strong association between $T$. cruzi 2 (Z2), Triatoma and rodents, and the terrestrial habitat (Table I). Importantly, T. cruzi 2 (Z2) has also been linked to

TABLE I

Triatomine habitats, hosts and trypanosomes

\begin{tabular}{llll}
\hline Triatomine & Silvatic Ecotope & Associated Trypanosomes & Associated Hosts \\
\hline Rhodnius species & Arboreal: palms & $\begin{array}{l}\text { Trypanosoma cruzi 1 [Z1] } \\
\text { T. rangeli }\end{array}$ & $\begin{array}{l}\text { Marsupial (Didelphis) } \\
\text { Marsupial (Didelphis) }\end{array}$ \\
Panstrongylus & Arboreal: not palms & T. cruzi 1 [Z1] & Didelphis \\
Panstrongylus & Terrestrial: burrows & T. cruzi [Z3] & Edentate Dasypus \\
& & & Marsupial Monodelphis \\
Triatoma & Terrestrial: rocks & & [Edentates? $^{\text {a }}$ \\
& & & Rodents (Cavia) \\
& & Primates (Leontocebus) \\
\hline
\end{tabular}

$a$ : edentates proposed as original hosts, see Table II and text. 
primates in southern Brazil (Leontocebus) (Fernandes et al. 1999).

Not surprisingly there are exceptions to these general associations, for example, T. cruzi 1 (Z1) has been isolated from $T$. spinolai in Chile (Miles et al. 1984) and T. cruzi 1 (Z1) has been isolated from $P$. geniculatus infesting pigsties in the Amazon basin (Valente et al. 1998).

THE EVOLUTION OF T. CRUZI 1 (Z1), T. CRUZI 2 (Z2) AND Z3

The observations above suggest a link between T. cruzi 1 (Z1) and Didelphis, and between T. cruzi 2 (Z2) and rodents or primates. The early mam- mal inhabitants of South America were the marsupials, and the placental edentate mammals (armadillos, sloths and anteaters) around 65 million years ago. However, fossil evidence indicates that rodents, primates and bats arrived about 25 million years later (Fig. 2). Furthermore rodents and primates probably reached South America from Africa, whereas marsupials and edentates migrated southwards from North America. Molecular evidence suggests that $T$. cruzi 1 (Z1) and T. cruzi 2 (Z2) diverged between 88 and 37 million years ago, although this requires confirmation with other data sets (Briones et al. 1999). If T. cruzi 2 (Z2) is in-

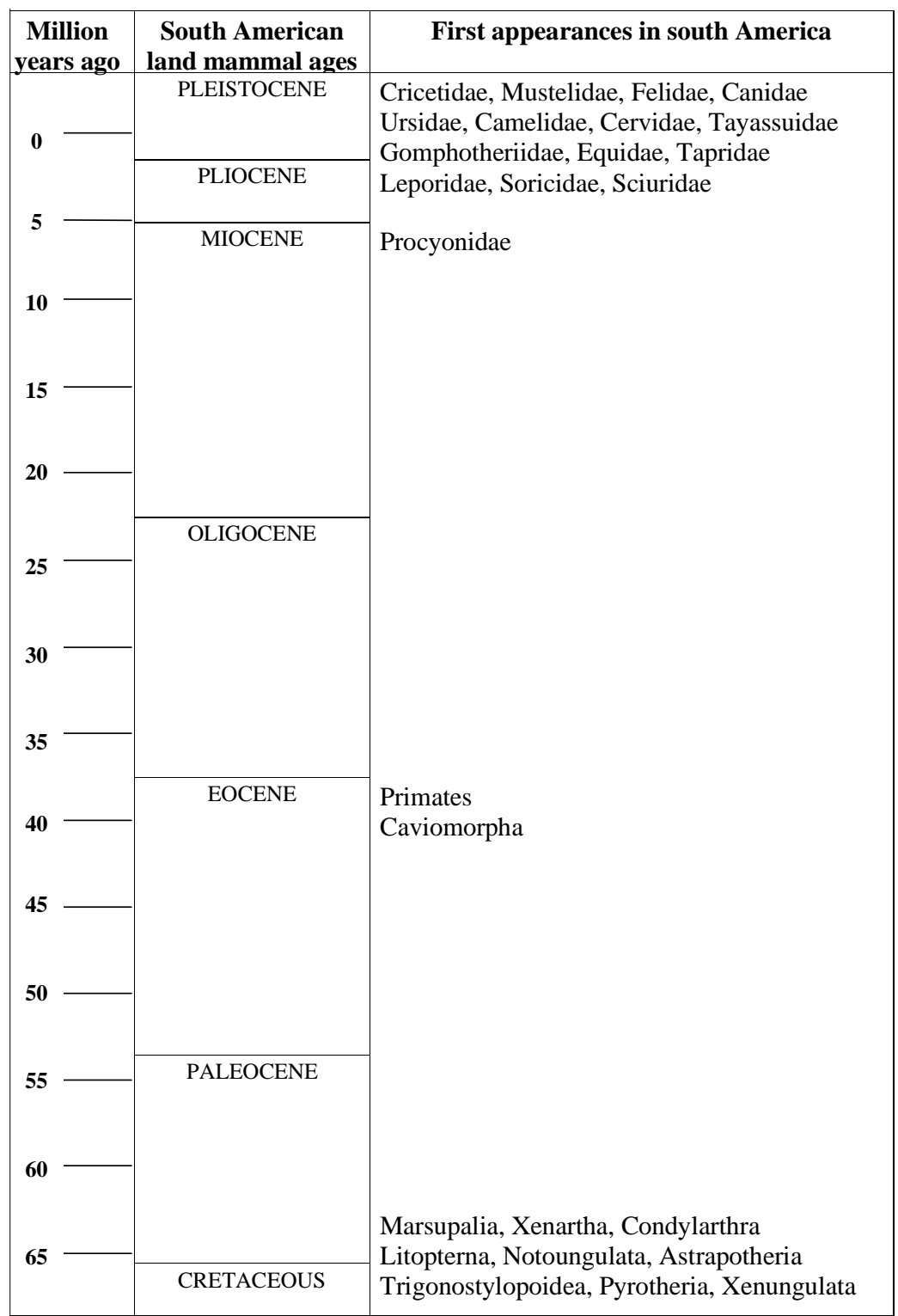

Fig. 2: marsupials and edentates are thought to have been present in South America 65 million years ago and 25 million years before the arrival of primates and rodents (based on Webb \& Marshall 1982). 
deed primarily associated with rodents or primates this implies a more recent evolutionary history than that of $T$. cruzi 1 (Z1).

Based on the observations described here we propose the following for the evolutionary histories of T. cruzi 1 (Z1), T. cruzi 2 (Z2) and Z3: (i) T. cruzi 1 (Z1) has evolved in an arboreal, palm tree habitat, with the triatomine tribe Rhodniini and also in association with the opossum Didelphis; (ii) both T. cruzi 2 (Z2) and Z3 evolved in a terrestrial habitat in burrows and in rocky locations, with the triatomine tribe Triatomini, in association with ground dwelling edentates, and possibly ground dwelling marsupials. Thus, edentates could be the primary host of both $T$. cruzi 2 (Z2) and Z3 and both the major subdivisions of $T$. cruzi could have been contemporary in South America up to 65 million years ago, and both have evolved in South America. If this hypothesis is correct, it follows that T. cruzi 2 (Z2) has reached rodents in later times through the shared terrestrial ecotope with edentates, and primates would also represent secondary hosts. We would expect that additional molecular evidence will confirm that Z3 is more closely related to $T$. cruzi 2 (Z2) than to $T$. cruzi 1 (Z1). An alternative hypothesis is that there was no early association between $T$. cruzi 2 (Z2) and edentates and that all T. cruzi 2 (Z2) populations are more recently derived from $T$. cruzi 1 (Z1) by host transfer into rodents, edentates and primates (Table II). Molecular dating evidence will be crucial (see below) to determining whether there is an ancient association between T. cruzi 2 (Z2) and edentates.

\section{TABLE II}

Proposed habitat and host associations for the two major subdivisions of Trypanosoma cruzi

$$
\text { (T. cruzi } 1 \text { and 2) }
$$

\begin{tabular}{|c|c|c|}
\hline $\begin{array}{l}\text { T. cruzi } 1 \\
\text { (Marsupial) }\end{array}$ & $\mathrm{Z} 1$ & $\begin{array}{l}\text { has evolved with Didelphis and } \\
\text { Rhodnius in an arboreal ecotope } \\
\text { (palms) }\end{array}$ \\
\hline $\begin{array}{l}\text { T. cruzi } 2 \\
\text { (Edentate) }\end{array}$ & $\begin{array}{l}\mathrm{Z} 2 \\
\mathrm{Z} 3\end{array}$ & $\begin{array}{l}\text { have both evolved initially with } \\
\text { edentates and Triatoma/Pans- } \\
\text { trongylus in a terrestrial ecotope }\end{array}$ \\
\hline T. cruzi 2 & $\mathrm{Z} 2$ & $\begin{array}{l}\text { has reached rodents through the } \\
\text { shared terrestrial ecotope with } \\
\text { edentates }\end{array}$ \\
\hline
\end{tabular}

\section{T. RANGELI, BAT SCHIZOTRYPANUM AND T. CONORHINI}

T. rangeli is virtually exclusively associated with the triatomine tribe Rhodniini and the genus Rhodnius, in which $T$. rangeli can reach the salivary glands to be transmitted by the bite, and not by faecal contamination. A common host of
T. rangeli is Didelphis, and geographical distribution of $T$. rangeli broadly corresponds with that of Rhodnius species and Didelphis. We therefore assume that like $T$. cruzi 1 (Z1), T. rangeli has evolved in an arboreal palm tree habitat with the Rhodniini and with Didelphis. Molecular evidence indicates that there is heterogeneity within the species $T$. rangeli. Further clarification of the relationship between $T$. rangeli and $T$. cruzi may depend on molecular phylogenetic studies.

The relatively recent arrival of bats to South America and their mobility by flight, suggests that T. cruzi like trypanosomes of bats are derived from either $T$. cruzi $1(\mathrm{Z} 1)$ or $T$. cruzi 2 (Z2)/Z3 by habitat sharing or, for insectivorous bats, by consumption of infected triatomine bugs. Several bat genera are common to South America and to the Old World. Molecular phylogenetic studies should reveal whether bat trypanosomes are closely related to one or both of the T. cruzi subdivisions and whether T. cruzi does indeed pre-date bat Schizotrypanum.

T. conorhini is unusual in that it is specifically associated with $R$. rattus and rubrofasciata, which may have spread from North America to the Old World. If T. conorhini also has a New World origin and affinities with $T$. cruzi we might expect molecular evidence to show that it is more closely related to $T$. cruzi 2 (Z2) than T. cruzi 1 (Z1).

\section{THE LINK WITH AUSTRALIA}

Stevens et al. (1999) have suggested an evolutionary link between a trypanosome of Australian marsupials (kangaroo) and T. cruzi. Australian marsupials are likely to be derived from one or a few species of the South American fauna which reached Australia via Antarctica around 45 million years ago. If we assume that the Triatominae evolved in South America (with the possible exception of the aberrant Indian genus Linshcosteus) it is perhaps not surprising that triatomine bugs did not reach Australia. Whilst of no proven evolutionary significance, it is interesting to note that Miles et al. (1982) commented on the kangaroolike terrestrial locomotion of the marsupial Metachirus nudicaudatus in Brazilian forest.

\section{THE EVOLUTION OF TRIATOMINE BUGS}

The occurrence of infective (metacyclic) $T$. cruzi in anal glands of the opossum Didelphis has suggested that $T$. cruzi might have been transmitted directly from marsupial to marsupial without a triatomine vector. In this case, triatomine bugs would have acquired $T$. cruzi infections only after T. cruzi had evolved as a blood parasite of marsupials. The alternative view is that $T$. cruzi has arisen from a flagellate parasite or symbiont of insects. Many flagellates, including kinetoplastids, are found 
in insects, and do not have a vertebrate host. Once again, molecular phylogenetics is likely to be fundamental to resolving this question.

Schofield (this volume) has quite logically suggested that the haematophagous triatomine bugs arose from predatory reduvids in response to the availability of vertebrate as well as invertebrate food sources in animal refuges and nesting sites. It is possible that the transition from predation to haematophagy may have occurred on more than one occasion. Several reduvid predators are morphologicaly similar to triatomines. However, the transition to haematophagy may not have been straightforward in that it presumably demands the evolution of anti-thrombins, to prevent coagulation interfering with feeding, and of less painful bites to allow prolonged feeding.

As marsupials and edentates were extant in South America at least 65 million years ago and were presumably using similar abundant arboreal and terrestrial nesting sites, we have no reason to believe that the triatomine transition to haematophagy did not take place long ago, and perhaps at a similar time, that is late in the Cretaceous or early in the Cenozoic (Paleocene, Eocene). It is significant to this debate to determine the evolutionary age of triatomine bugs. Accordingly we have begun to apply an extensive molecular phylogenetics approach to elucidate the evolution and ecology of triatomines using both mitochondrial DNA and nuclear targets.

\section{VECTOR PHYLOGENETICS}

The phylogenetic analysis of DNA sequence data has proved a powerful method for addressing both macro- and micro-evolutionary hypotheses for the origins, epidemiological structure and population dynamics of both arthropod vectors and their specific parasites (Garcia \& Powell 1998, Stothard et al. 1998, Lyman et al. 1999, Stevens \& Gibson 1999, Stevens et al. 1999). The questions raised so far fall into the macro-evolutionary category, however questions of evolution in "micro-time scales" are receiving increasing attention in the field due to their usefulness in determining the population dynamics of triatomine bugs (Harry et al. 1998).

Our investigation of the epidemiology of Chagas disease from the perspective of vector evolution has two approaches: firstly, as a study of macro-evolution, that is the molecular reconstruction of the vector in relation to other insect vectors, as well as estimating the evolutionary timescale involved, and secondly as a study of the micro-evolution of triatomine bug population dynamics. Triatomine molecular approaches are topical largely because of the successful control of Chagas disease transmission by the eradication of domestic $T$. infestans in the recent southern cone programme (Dias \& Schofield 1999). Our initial analysis describes the evolution of the triatomines with respect to the other major haematophagous vectors through a mitochondrial DNA phylogeny comprising Aedes, Culex and Anopheles mosquitoes, biting midges, black flies, and tsetse. To our knowledge this represents the largest phylogeny of haematophagous vectors between genera. The phylogeny is divided into two clades one containing the homometabolous insects and the other the hemimetabolous insects. The evolution of disease transmission is a question that can be addressed by phylogeny, that is the evolution of faecal transmission (cophageny) of vector-borne diseases in comparison to that of salivary transmitted parasites. Triatomines are anomalous as an arthropod vector as they transmit trypanosomes both through contaminated faeces (T. cruzi) and salivary transmission (T. rangeli). A comparative analysis of the five vectors phylogeny with the inclusion of other insects, particularly termites, harboring protozoan endosymbionts provides several lines of evidence that faecal transmission is ancestral. In addition, triatomines demonstrate exclusive cophageny for bacterial symbionts (Durvasula et al. 1999), and predominant cophageny for the triatomine pathogen Blastocrithidia triatomae (Schaub et al. 1989). The evidence suggests that the original bug-borne trypanosome "hijacked" the natural mechanism of endosymbiont transmission.

A second focus of our macro-evolutionary studies has concerned evolutionary dating. The dating of insects remains problematic due to the relative scarcity of their fossil record (Ross \& Briggs 1993) and the surprising absence of molecular clocks even at the family level. Following an extensive search we obtained a single genetic locus demonstrating clock behaviour both between lineages (constant rates of evolution) and between nodes (the congruence of the fossil record) for all available sequence data within the class Insecta. The molecular clock phylogeny describes the deepest split within the triatomines between Rhodnius and Triatoma as being ancient, occurring before the arrival of bats and rodents into South America. Combined with the niche specialization of triatomines a unified picture of an ancient family emerges. The molecular clock has much broader implications for other insect groups, although our chief concern is the ability to obtain robust dates for the species divergences within the Triatominae. This would elucidate the time-scale for the evolution of the niche specialization previously described, and would include the time for the evolution of bugs into domestic habitats. 
The evolutionary understanding of the triatomines is furthered by our recent observation of the monophyletic origin of anti-thrombin salivary proteins within the triatomine family and provides compelling evidence that the evolution of haematophagous behaviour evolved from a single ancestor. A large focus of research interest concerns the phylogenetic status of predatory reduviids, some of which have been postulated to split the monophyly of the triatomines. Such an occurrence would be of particular evolutionary interest for haematophagous vectors.

The focus of our micro-evolutionary studies concerns the movement of bugs between sylvatic and domestic ectopes. To address this issue we developed a salivary protein phylogeny based on anti-thrombin proteins for all the major species in the genus Rhodnius, and we are currently developing further salivary protein genetic markers. The current phylogeny was congruent with the corresponding mitochondrial phylogenies already described by Lyman et al. (1999), with the single exception, of $R$. neglectus which for salivary protein phylogenies forms a sister group with $R$. nasutus. The salivary protein genetic marker provides high genetic resolution for the genus Rhodnius, resulting in robust bootstrap support for even closely related $R$. prolixus populations captured in Nicaragua and Honduras. Moreover, the ability to distinguish between $R$. prolixus populations from adjacent countries appears to provide a considerable advantage over the starch gel electrophoresis of salivary haeme proteins, which were unable to distinguish Honduras $R$. prolixus from Venezuelan populations (Sores et al. 1998).

The aim of both our evolutionary approaches is to adapt evolutionary dating into a micro-evolutionary time scale using the high resolution salivary protein genetic markers. The strategy would potentially determine the age of the split between triatomines that have evolved within an exclusively sylvatic ecotope and those that have irreversibly adapted to a domestic ectope e.g. T. infestans. Robust estimates of micro-evolutionary time between or within species complexes represents important information for assessing the feasibility of vector eradication by insecticide programmes and success would be a seminal contribution to resolving haematophagous vector population dynamics.

Ultimately it is the combination of both vector and parasite phylogenies as well as the interface between macro-evolution and micro-evolution that forms part of a cross-disciplinary approach for understanding Chagas disease epidemiology. This in turn provides a comprehensive framework for advising South American governments on cost effective control strategies for Chagas disease through the recently formed ECLAT network. The research reviewed here is an integral component of the ECLAT objectives.

\section{ACKNOWLEDGEMENTS}

To Chris Schofield, José Jurberg, Aldo Valente, Mariela Torres-Torres, Ben Beard, Cesar Cuba Cuba, Russell Stothard and Hooman Momen for supplying bug specimens and/or for helpful discussions. To Susi Solis for assistance as part of her ALFA training programme.

\section{REFERENCES}

Anon 1999. Recommendations from a Satellite Meeting. International Symposium to commemorate the 90th anniversary of the discovery of Chagas disease. April 11-16 1999, Rio de Janeiro, Brazil. Mem Inst Oswaldo Cruz 94 (Suppl. 1): 429-432.

Bastrenta B, Bosseno MF, Barnabe C, Tibayrenc M, Breniere SF 1999. Restriction fragment length polymorphism of $195 \mathrm{bp}$ repeated satellite DNA of Trypanosoma cruzi supports the existence of two phylogenetic groups. Mem Inst Oswaldo Cruz 94: 323328.

Briones MRS, Souto RP, Stolf BS, Zingales B 1999. The evolution of two Trypanosoma cruzi subgroups inferred from rRNA genes can be correlated with the interchange of American mammalian faunas in the Cenozoic and has implications to pathogenicity and host specificity. Mol Biochem Parasitol 104: 219-232.

Carcavallo RU, Giron IG, Jurberg J, Lent H 1998. Atlas of Chagas Disease Vectors in the Americas, Editora Fiocruz, Rio de Janeiro.

Carrasco HJ, Frame IA, Valente SA, Miles MA 1996. Genetic exchange as a possible source of genomic diversity in sylvatic populations of Trypanosoma cruzi. Am J Trop Med Hyg 54: 418-424.

Chapman MD, Baggaley RC, Godfrey-Fausset PF, Malpas TJ, White G, Canese J, Miles MA 1984. Trypanosoma cruzi from the Paraguayan Chaco: isoenzyme profiles of strains isolated at Makthlawaiya. J Protozool 31: 482-486.

Dias JCP, Schofield CJ 1999. The evolution of Chagas disease (American trypanosomiasis) control after 90 years since Carlos Chagas discovery. Mem Inst Oswaldo Cruz 94 (Suppl. 1): 103-121.

Durvasula RV, Kroger A, Goodwin M, Panackal A, Kruglov O, Taneja J, Gumbs A, Richards FF, Beard CB, Cordon-Rosales C 1999. Strategy for introduction of foreign genes into field populations of Chagas disease vectors. Proc Natl Acad Sci 92: 937-943.

Fernandes O, Mangia RH, Lisboa CV, Pinho AP, Morel CM, Zingales B, Campbell DA, Jansen AM 1999. The complexity of the sylvatic cycle of Trypanosoma cruzi in Rio de Janeiro state (Brazil) revealed by the non-transcribed spacer of the mini-exon gene. Parasitology 118: 161-166.

Garcia BA, Powell JR 1998. Phyogeny of species of Triatoma (Hemiptera:Reduviidae) based on mitochondrial DNA sequences. J Med Entomol 35: 232 238.

Harry M, Poyet G, Romana CA, Solignac M 1998. Iso- 
lation and characterisation of microsatellite markers in the bloodsucking bug Rhodnius pallescens (Heteroptera:Reduviidae). Mol Ecol 7: 1784-1786.

Lent H, Wygodzinsky P 1979. Revision of the Triatominae (Hemiptera:Reduviidae) and their significance as vectors of Chagas disease. Bull Am Mus Nat Hist 163: 520.

Lyman DE, Monteiro FA, Escalante AA, CordonRosales C, Wesson DM, Dujardin JP, Beard CB 1999. Mitochondrial DNA sequence variation among triatomine vectors of Chagas disease. Am J Trop Med Hyg 60: 377-386.

Miles MA 1979. Transmission cycles and the heterogeneity of Trypanosoma cruzi in Amazonian forest. In WHR Lumsden, DA Evans (eds), Biology of the Kinestoplastida, Vol. 2, Academic Press, London, New York, San Francisco, p. 117-196.

Miles MA, Apt W, Widmer G, Povoa MAM, Schofield CJ 1984. Isozyme heterogeneity and numerical taxonomy of Trypanosoma cruzi stocks from Chile. Trans $R$ Soc Trop Med Hyg 78: 526-535.

Miles MA, Arias JR, De Souza AA 1983. Chagas disease in the Amazon Basin V. Periurban palms as habitats of Rhodnius robustus and Rhodnius pictipes - triatomine vectors of Chagas disease. Mem Inst Oswaldo Cruz 78: 391-398.

Miles MA, De Souza AA, Povoa M 1981a. Chagas disease in the Amazon Basin III. Ecotopes of ten triatomine bug species (Hemiptera:Reduviidae) from the vicinity of Belém, Pará State, Brazil. J Med Entomol 18: 266-278.

Miles MA, De Souza AA, Povoa MM 1981b. Mammal tracking and nest location in Brazilian forest with an improved spool-and-line device. J Zool Lond 195: 331-347.

Miles MA, De Souza AA, Povoa MM 1982. O ecótopo de Panstrongylus megistus (Hemiptera:Reduviidae) na floresta do horto (Rio de Janeiro). Rev Brasil Biol 42: 31-35.

Povoa MM, De Souza AA, Naiff RD, Arias JR, Naiff MF, Biancardi CB, Miles MA 1984. Chagas disease in the Amazon Basin IV. Host records of Trypanosoma cruzi zymodemes in the States of
Amazonas and Rondônia, Brazil. Ann Trop Med Parasitol 78: 479-487.

Ross AJ, Briggs DEG 1993. Arthropoda (Euthycarcinoidea and Mriapoda). In MJ Benton, The Fossil Record 2, Chapman and Hall, London, p. 257-362.

Schaub GA, Boker CA, Jensen C, Reduth D 1989. Cannibalism and coprophagy are modes of transmission of Blastocrithidia triatomae (trypanosomatidae) between triatomines. J Protozool 36: 171-175.

Sores RPP, Gontijo NF, Romanha AJ, Diotaiuti L, Pereira MH 1998. Salivary heme proteins distinguish Rhodnius prolixus from Rhodnius robustus (Hemiptera:Reduviidae:Triatominae). Acta Trop 71: 285-291.

Stevens JR, Noyes HA, Dover GA, Gibson WC 1999. The ancient and divergent origins of the human pathogenic trypanosomes, Trypanosoma brucei and T. cruzi. Parasitology 118: 107-116.

Stevens JR, Gibson W 1999. The molecular evolution of trypanosomes. Parasitol Today 15: 432-437.

Stothard JR, Frame IA, Miles MA 1999. Genetic diversity and genetic exchange in Trypanosoma cruzi: dual drug-resistant "progeny" from episomal transformants. Mem Inst Oswaldo Cruz 94 (Suppl. 1): 189-193.

Stothard JR, Yamamoto Y, Cherchi A, Garcia AL, Valente SAS, Schofield CJ, Miles MA 1998. A preliminary survey of mitochondrial sequence variation in Triatominae (Hemiptera:Reduviidae) using polymerase chain reaction-based single strand conformational polymorphism (SSCP) analysis and direct sequencing. Bull Ent Res 88: 553-560.

Valente VC, Valente SAS, Noireau F, Carrasco HJ, Miles MA 1998. Chagas disease in the Amazon Basin: association of Panstrongylus geniculatus (Hemiptera:Reduviidae) with domestic pigs. J Med Entomol 35: 99-103.

Webb SD, Marshall LG 1982. Historical biogeography of recent South American land mammals. In MA Mares, HH Genoways (eds), Mammalian Biology in South America, Vol. 6, Special Publication Series, Pymatuning Laboratory of Ecology, University of Pittsburgh. p. 39-52. 